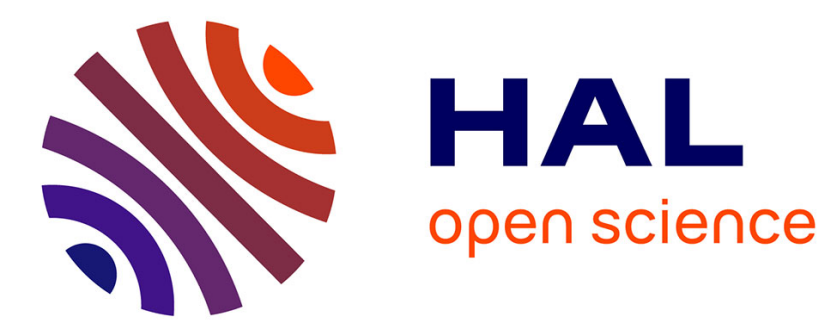

\title{
Synthesis, crystal and electronic structures of La3Cr2N6
}

François Cheviré, Chinmoy Ranjan, Francis J. Disalvo

\section{To cite this version:}

François Cheviré, Chinmoy Ranjan, Francis J. Disalvo. Synthesis, crystal and electronic structures of La3Cr2N6. Solid State Communications, 2009, 149 (7-8), pp.273-276. 10.1016/j.ssc.2008.12.004 . hal-00862142

\section{HAL Id: hal-00862142 \\ https://hal.science/hal-00862142}

Submitted on 22 Sep 2015

HAL is a multi-disciplinary open access archive for the deposit and dissemination of scientific research documents, whether they are published or not. The documents may come from teaching and research institutions in France or abroad, or from public or private research centers.
L'archive ouverte pluridisciplinaire HAL, est destinée au dépôt et à la diffusion de documents scientifiques de niveau recherche, publiés ou non, émanant des établissements d'enseignement et de recherche français ou étrangers, des laboratoires publics ou privés. 


\title{
Synthesis, crystal structure and electronic structure of
}

\section{$\mathbf{L a}_{3} \mathrm{Cr}_{2} \mathbf{N}_{6}$.}

François Cheviré, Chinmoy Ranjan, Francis J. DiSalvo*.

Department of Chemistry and Chemical Biology, Cornell University, Ithaca, NY 14853, USA

Phone: +1 607-255-7238

Fax: +1 607-255-4137

*fjd3@cornell.edu

\section{Keywords}

Chemical synthesis; Crystal growth; Crystal and structure symmetry

\begin{abstract}
The rare earth - transition metal ternary nitride $\mathrm{La}_{3} \mathrm{Cr}_{2} \mathrm{~N}_{6}$ was synthesized from the elements and an excess of sodium and gallium at $900^{\circ} \mathrm{C}$ in a sealed niobium tube. This compound crystallizes in the tetragonal space group I4/mmm (No. 139) with $a=$ $3.8525(5) \AA$ and $c=20.508(4) \AA$. It is isostructural with the recently discovered ternary nitride $\mathrm{R}_{3} \mathrm{M}_{2} \mathrm{~N}_{6}(\mathrm{R}=\mathrm{La}, \mathrm{Ce}$ or $\mathrm{Pr} ; \mathrm{M}=\mathrm{V}, \mathrm{Nb}$ or Ta $)$ and with the high $T_{\mathrm{c}}$ superconducting copper oxide $\mathrm{La}_{2-\mathrm{x}} \mathrm{Sr}_{\mathrm{x}} \mathrm{CaCu}_{2} \mathrm{O}_{6}$. Band structure calculations using density functional theory show that $\mathrm{La}_{3} \mathrm{Cr}_{2} \mathrm{~N}_{6}$ contains $\mathrm{CrN}_{2}$ conducting layers.
\end{abstract}




\section{Introduction}

Among the numerous ternary or quaternary nitrides synthesized over the past 30 years, only a few compounds containing rare earth metals have been described [1], [2], [3], [4], [5], [6], [7], [8], [9] and [10]. Recently, we have reported the first rare earth nitridogallate compound, $\mathrm{La}_{2} \mathrm{GaN}_{3}$ that contains infinite chains of corner-sharing $\left[\mathrm{GaN}_{2} \mathrm{~N}_{2 / 2}\right]^{6-}$ tetrahedra [10]. Of the known rare earth transition metal ternary nitrides, most exhibit structures related to the perovskite-type, especially of the RuddlesdenPopper series. $\mathrm{TaThN}_{3}[6]$ has the perovskite structure while the $\mathrm{R}_{2} \mathrm{MN}_{3}$ nitrides $(\mathrm{R}=\mathrm{U}$, Th or Ce; $\mathrm{M}=\mathrm{Cr}$ or $\mathrm{Mn}$ ) adopt a defect $\mathrm{K}_{2} \mathrm{NiF}_{4}$ structure [4], [5] and [7]. More recently, the $\mathrm{R}_{3} \mathrm{M}_{2} \mathrm{~N}_{6}$ compounds ( $\mathrm{R}=\mathrm{La}$, Ce or $\mathrm{Pr}$; $\mathrm{M}=\mathrm{Nb}$ or Ta) [9] and $\mathrm{La}_{3} \mathrm{~V}_{2} \mathrm{~N}_{6}$ [10] have been found to crystallize in a defect $\mathrm{Sr}_{3} \mathrm{Ti}_{2} \mathrm{O}_{7}$ type structure. Here we report the synthesis and both the crystal and electronic structures of a new member of the above mentioned $\mathrm{R}_{3} \mathrm{M}_{2} \mathrm{~N}_{6}$ series with $\mathrm{R}=\mathrm{La}$ and $\mathrm{M}=\mathrm{Cr}$.

\section{Experimental}

Two different types of crystals-a few black metallic plates of $\mathrm{La}_{3} \mathrm{Cr}_{2} \mathrm{~N}_{6}$ and a large amount of black silvery octahedral crystals of $\mathrm{La}_{3} \mathrm{Cr}_{10-x} \mathrm{~N}_{11}$ [4]-were obtained from the same reaction using the following procedure. Due to the air sensitivity of the reagents, all manipulations were carried out in an argon-filled glove box. $\mathrm{Na}, \mathrm{Ga}, \mathrm{La}$, $\mathrm{Cr}$ and $\mathrm{NaN}_{3}$ were placed into a niobium tube $(\mathrm{OD} \approx 1 \mathrm{~cm}$, length $\approx 12 \mathrm{~cm})$ such as the atomic ratios of Na:Ga:La:Cr: $\mathrm{N}_{2} 2$ were 6:4:1:1:3. The corresponding masses are $\mathrm{Na}$ (Aldrich, A.C.S reagent grade) $83 \mathrm{mg}$, Ga (99.99\%) $200 \mathrm{mg}$, La (filled from rod, Jonhson Matthey Company) $100 \mathrm{mg}, \mathrm{Cr}(99.9 \%) 37 \mathrm{mg}$ and $\mathrm{NaN}_{3}(99.9 \%) 47 \mathrm{mg}$. The niobium container was sealed under argon in a Centorr Associates arc furnace and then 
itself sealed under vacuum in a fused silica tube in order to be protected from subsequent oxidation during heating. The silicon tube was then placed into a muffle furnace, heated up to $900{ }^{\circ} \mathrm{C}$ over $15 \mathrm{~h}$, and held at temperature for $36 \mathrm{~h}$. Then the furnace was cooled to RT in $100 \mathrm{~h}$. Following the reaction, unreacted sodium was removed by evaporation from the products by heating the niobium tube to $350{ }^{\circ} \mathrm{C}$ under a vacuum of $\sim 10^{-6}$ bar for $8 \mathrm{~h}$. In order to increase the amount and the sizes of the $\mathrm{La}_{3} \mathrm{Cr}_{2} \mathrm{~N}_{6}$ crystals, several reactions with different elemental ratios and different experimental conditions (temperature and times) have been carried out, but all were unsuccessful at producing a significantly larger mole fraction of the desired product or larger crystal sizes. The products of the reaction were analyzed with powder X-ray diffraction using a Scintag $2000 \theta-\theta \theta-\theta$ diffractometer with $\mathrm{CuK} \alpha$ radiation. The X-ray sample was prepared in an argon-filled glove box and covered with Mylar film to prevent aerial oxidation. Single crystal X-ray diffraction data were obtained using a Brucker X8 Apex II diffractometer equipped with 4K CCD detector and graphite monochromatized MoK $\alpha$ radiation $(\lambda=0.07107 \AA \lambda=0.07107 \AA)$. The Brucker software package SAINT [11] was used to integrate the data, an empirical absorption correction was applied using SADABS [12] and the initial input files for solving the structure prepared by XPREP [13]. The integrated data were analyzed with the SHELX97 [14] suite of programs within WinGX [15]. The La:Cr ratio of the both lanthanum chromium nitrides were determined by electron microprobe analysis, performed with a JEOL 8900 electron microprobe.

GGA-PW91 [16] and [17] DFT-based periodic calculations were carried out in a PAW [18] and [19] basis using the VASP [20] package. The plane wave cut-off energy was fixed at $450 \mathrm{eV}$. A $10 \times 10 \times 2$ Monkhorst Pack [21] grid of KK points was 
used. The optimized geometry used to calculate the band structure and density of states varied less than $1 \%$ from the experimental values (optimized lattice parameters: $\left.a=b=3.821 \AA \mathrm{a}=\mathrm{b}=3.821 \AA, c=20.341 \AA \mathrm{c}=20.341 \AA, \alpha=\beta=\gamma=90^{\circ} \alpha=\beta=\gamma=90 \circ\right)$. The Wigner Seitz radii used to calculate projected densities of states were $1.535 \AA$ for La, $1.323 \AA$ for $\mathrm{Cr}$ and $0.741 \AA$ for N. All electronic iterations were converged within $10^{-5} \mathrm{eV}$.

\section{Results and Discussion}

After the sodium was removed from the sample, the tube was moved back into the argon-filled glove box. The remaining product was a dark gray, silvery mass in which small crystals were apparent by tilting the collection of solids. A fraction of the product was ground in an agate mortar for powder X-ray diffraction analysis, and the powder pattern revealed many peaks that were assigned to known phases $\mathrm{Na}_{x} \mathrm{Ga}_{y}$, $\mathrm{La}_{x} \mathrm{Ga}_{y}$ and $\mathrm{Cr}_{x} \mathrm{Ga}_{y}$ and to the nitrides $\mathrm{LaN}$ and $\mathrm{La}_{3} \mathrm{Cr}_{10-x} \mathrm{~N}_{11}$ [4]. Another sample of the reaction product was placed into polybutene oil for inspection under an optical microscope. Two different types of crystals were observed: a few thin black metallic plates and numerous well-shaped black silvery octahedral crystals. The latter were found to be the known $\mathrm{La}_{3} \mathrm{Cr}_{10-x} \mathrm{~N}_{11}$ nitride by XRD. Several of the black metallic plates were analyzed and all were consistent with a tetragonal symmetry. A suitable crystal with approximate $100 * 60 * 20 \mu \mathrm{m}^{3}$ dimensions was chosen for long data collection. Its structure was solved in I4/mmmI4/mmm (No. 139). Details of the refinement are shown in Table 1. No extra symmetry was found by ADDSYM [22]. The atomic coordinates were standardized with STRUCTURE TIDY [23] and are shown in Table 2. Some relevant bond lengths and the anisotropic displacement factors are detailed in Table 3 and Table 4, respectively. In order to verify the elemental 
composition found by the single crystal XRD solution, semi-quantitative electron microprobe spectroscopy measurement was carried out and revealed a $\mathrm{La}: \mathrm{Cr}$ ratio of 1.7:1. The difference from the theoretical $1.5: 1$ ratio is due to the fact that no standards were used for internal calibration. No signal corresponding to sodium, gallium or niobium was observed. The presence of nitrogen was confirmed by wavelength dispersive spectroscopy.

$\mathrm{La}_{3} \mathrm{Cr}_{2} \mathrm{~N}_{6}$ is isostructural with the ternary nitrides $\mathrm{R}_{3} \mathrm{M}_{2} \mathrm{~N}_{6}(\mathrm{R}=\mathrm{La}, \mathrm{Ce}$ or Pr; $\mathrm{M}=\mathrm{V}, \mathrm{Nb}$ or $\mathrm{Ta}$ ) [8] and [9] and with the double layer superconducting cooper oxides $\mathrm{La}_{2-x} \mathrm{Sr}_{x} \mathrm{CaCu}_{2} \mathrm{O}_{6}$ [24]. Fig. 1 gives a perspective view of the structure that is related to the one of the Ruddlesden-Popper phase $\mathrm{Sr}_{3} \mathrm{Ti}_{2} \mathrm{O}_{7}$, i.e. $\mathrm{Sr}_{n+1} \mathrm{Ti}_{n} \mathrm{O}_{3 n+1}$ with $\mathrm{n}=2$ [25]. Compared to the oxo-titanate, one nitrogen position is vacant in the perovskite doublelayers of $\mathrm{La}_{3} \mathrm{Cr}_{2} \mathrm{~N}_{6}$. While in $\mathrm{Sr}_{3} \mathrm{Ti}_{2} \mathrm{O}_{7}$ the titanium atoms are located in the center of an octahedron, the chromium atoms in $\mathrm{La}_{3} \mathrm{Cr}_{2} \mathrm{~N}_{6}$ are located slightly above the basal plane of a nitrogen square pyramid. These pyramids form extended $2 \mathrm{D}{ }_{\infty}^{2}\left[\mathrm{CrN}_{4 / 2} \mathrm{~N}\right]$ $\infty 2\left[\mathrm{CrN}_{4 / 2} \mathrm{~N}\right]$ layers via corner sharing. The average rare earth-nitrogen distance La$\mathrm{N} \approx 2.67 \AA$ in $\mathrm{La}_{3} \mathrm{Cr}_{2} \mathrm{~N}_{6}$ is similar to that found in the binary nitrides $\mathrm{LaN}$ ( $\mathrm{La}-$ $\mathrm{N} \approx 2.65 \AA$ ) or the ternary nitride $\mathrm{La}_{2} \mathrm{GaN}_{3}$ [10]. But the average chromium-nitrogen distance $\mathrm{Cr}-\mathrm{N} \approx 1.94 \AA$ is slightly shorter than what is reported for $\mathrm{CrN}(\mathrm{Cr}-\mathrm{N} \approx 2.07 \AA)$ and can be compared to those found in another rare earth chromium nitride, $\mathrm{Ce}_{2} \mathrm{CrN}_{3}$, a structure that is related to another member of the Ruddlesden-Popper phases, $\mathrm{Sr}_{2} \mathrm{TiO}_{4}$ $(\mathrm{n}=1)$ with a defective $\mathrm{K}_{2} \mathrm{NiF}_{4}$ structure: $\mathrm{Cr}-\mathrm{N} \approx 1.99 \AA$ [4].

The total and projected densities of states calculated for $\mathrm{La}_{3} \mathrm{Cr}_{2} \mathrm{~N}_{6}$ are shown in Fig. 2. The La d-bands lie well above the Fermi level, i.e. $\mathrm{La}^{3+}$, which cuts through the Cr d-bands, predicting metallic behavior, i.e. formally $\mathrm{Cr}^{4.5+}$. Around the Fermi level, 
the important features of the band structure of $\mathrm{La}_{3} \mathrm{Cr}_{2} \mathrm{~N}_{6}$ are determined by the nitrogen chromium interactions within the ${ }_{\infty}^{2}\left[\mathrm{CrN}_{4 / 2} \mathrm{~N}\right]$ layer.

\section{Acknowledgment}

This work was supported by NSF grant number DMR-0602526. We thank Dr. Emil Lobkovsky for help with the single crystal data collection and structure solution, and John hunt for help with the SEM Microprobe. The Microprobe is supported by the Cornell Center for Materials Research Shared Experimental Facilities, and funded through the National Science foundation Materials Research Science and Engineering program DMR-0520404. 


\section{References}

[1] K. E. Spear, J.M. Leitnaker, High Temp. Sci. 3 (1971) 29-40.

[2] R. Marchand, V. Lemarchand, J. Less-Common Met. 80 (1981) 157-163.

[3] O. Isnard, S. Miraglia, J.L. Soubeyroux, D. Fruchart, J. Algebraic Combin. 190 (1992) 129-135.

[4] S. Broll, W. Jeitschko, Z. Naturforsch. B50 (1995) 905-912.

[5] R. Niewa, G.V. Vajenine, F.J. DiSalvo, H. Luo, W.B. Yelon, Z. Naturforsch. B 53 (1998) 63-34.

[6] N. Brese, F.J. DiSalvo, J. Solid State Chem. 120 (1995) 378-380.

[7] R. Benz, W.H. Zachariansen, J. Nucl. Mater. 10 (1970) 109-113.

[8] Z.A. Gal, L. Cario, F.J. DiSalvo, Solid State Sci. 5 (2003) 1033-1036.

[9] L. Cario, Z.A. Gal, T.P. Braun, F.J. DiSalvo, B. Blaschkowski, H.-J. Meyer, J. Solid State Chem. 162 (2001) 90-95.

[10] F. Cheviré, F.J. DiSalvo, J.Alloys Comp. 457 (2008) 372-375.

[11] Brucker, SAINT plus: Software for the CCD system, Brucker Analytical X-ray system,Madison,WI,2003.

[12] G.M. Sheldrick, SADABS, Institute fur Anorganische Chemie der Universitat Gottingen,Gottingen,Germany,2003.

[13] Brucker, XPREP (Version6.14), Brucker Analytical X-ray system, Madison, WI, 2003.

[14] G.M. Sheldrick, SHELXS97 and SHELXL97, University of Gottingen, Germany, 1997.

[15] L.J. Farrugia, J. Appl. Crystallogr. 32 (1999) 837-838.

[16] J.P. Perdew, et al., Phys. Rev. B46 (1992) 6671. 
[17] J.P. Perdew, et al., Phys. Rev. B48 (1993) 4978.

[18] P.E. Blöchl, Phys. Rev. B50 (1994) 17953.

276

[19] G. Kresse, D. Joubert, Phys. Rev. B59 (1999) 1758.

[20] G. Kresse, J. Hafner, Phys. Rev. B47 (1993) 558; G. Kresse, J. Hafner, Phys. Rev. B49 (1994) 14251; G. Kresse, J. Furthmüller, Comput. Mater. Sci. 6 (1996) 15; G.

Kresse, J. Furthmüller, Phys. Rev. B54 (1996) 11169.

[21] H.J. Monkhorst, J.D. Pack, Phys. Rev. B13 (1976) 5188.

[22] L.J. Farrugia, J. Appl. Crystallogr. 32 (1999) 837-838.

[23] L.M. Gelato, E. Parthè, J. Appl. Crystallogr. 20 (1987) 139.

[24] R.J. Cava, B. Batlogg, R. B. Van Dover, J.J. Krajewski, J.V. Waszczak, R.M.

Fleming, W.F. Peck Jr, L.W. Rupp Jr., P. Marsh, A.C.W.P. James, L.F. Schneemeyer, Nature (London) 345 (6276) (1990) 602-604.

[25] S.N. Ruddlesden, P. Popper, Acta Crystallogr. 11 (1958) 54-55. 


\section{Figures and tables captions}

Figure 1: Structure of $\mathrm{La}_{3} \mathrm{Cr}_{2} \mathrm{~N}_{6}$ shown in perspective along aa axis. The chromium and the lanthanum coordination environments are shown on the right of the figure with the main inter-atomic distances.

Figure 2: Total and projected densities of states (DOS) calculated for $\mathrm{La}_{3} \mathrm{Cr}_{2} \mathrm{~N}_{6}$ with DFT.

Table 1: Crystal data and structure refinement for $\mathrm{La}_{3} \mathrm{Cr}_{2} \mathrm{~N}_{6}$.

Table 2: Atomic coordinates and values of $\mathrm{U}_{\mathrm{eq}} \mathrm{Ueq}$, the equivalent isotropic displacement parameter $\left(\AA^{2} \times 10^{3}\right)$, for $\mathrm{La}_{3} \mathrm{Cr}_{2} \mathrm{~N}_{6}$.

Table 3: Selected bond lengths for $\mathrm{La}_{3} \mathrm{Cr}_{2} \mathrm{~N}_{6}(\AA)$.

Table 4: Anisotropic displacement factors for $\mathrm{La}_{3} \mathrm{Cr}_{2} \mathrm{~N}_{6}$. 
Figure 1

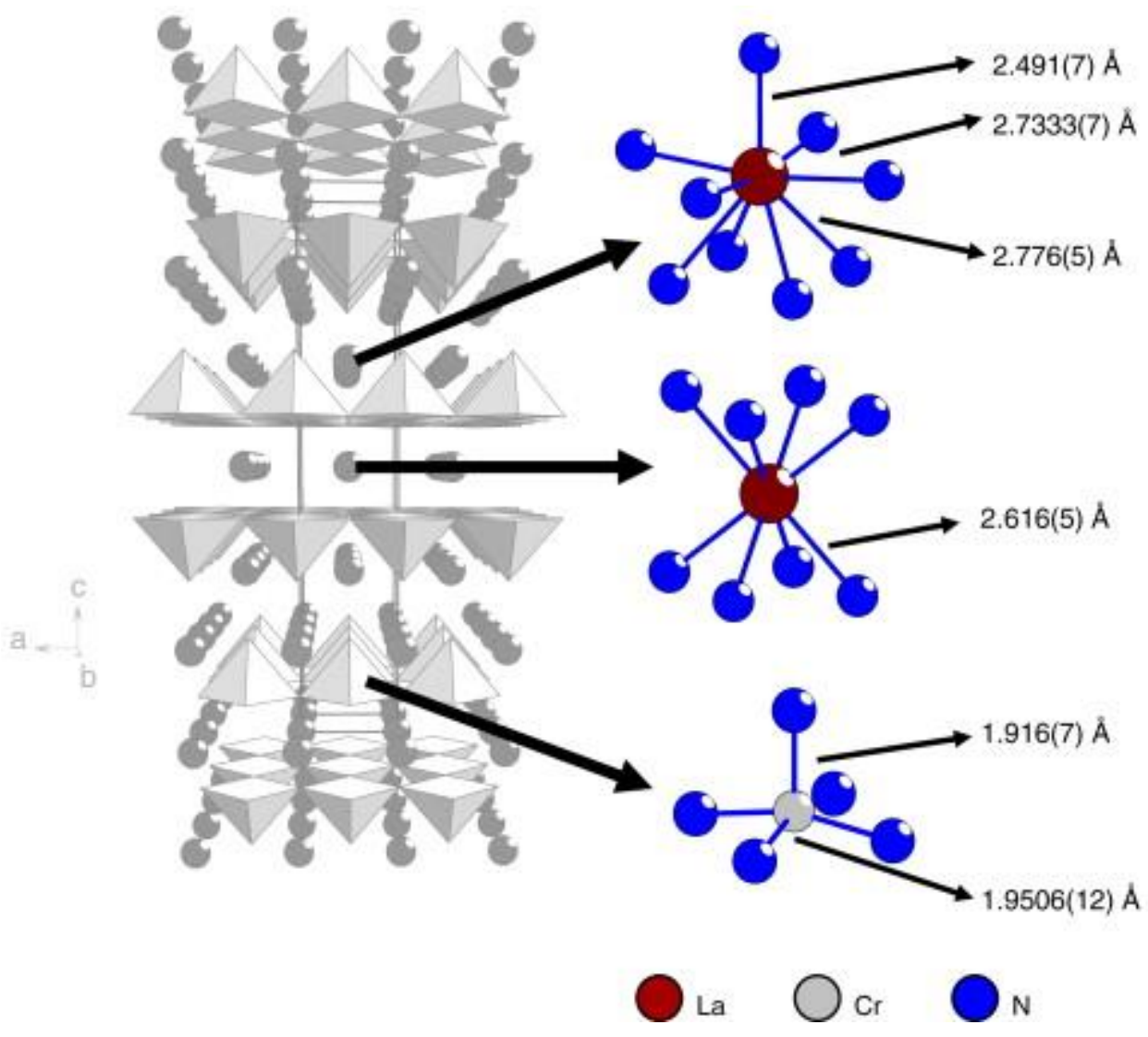


Figure 2

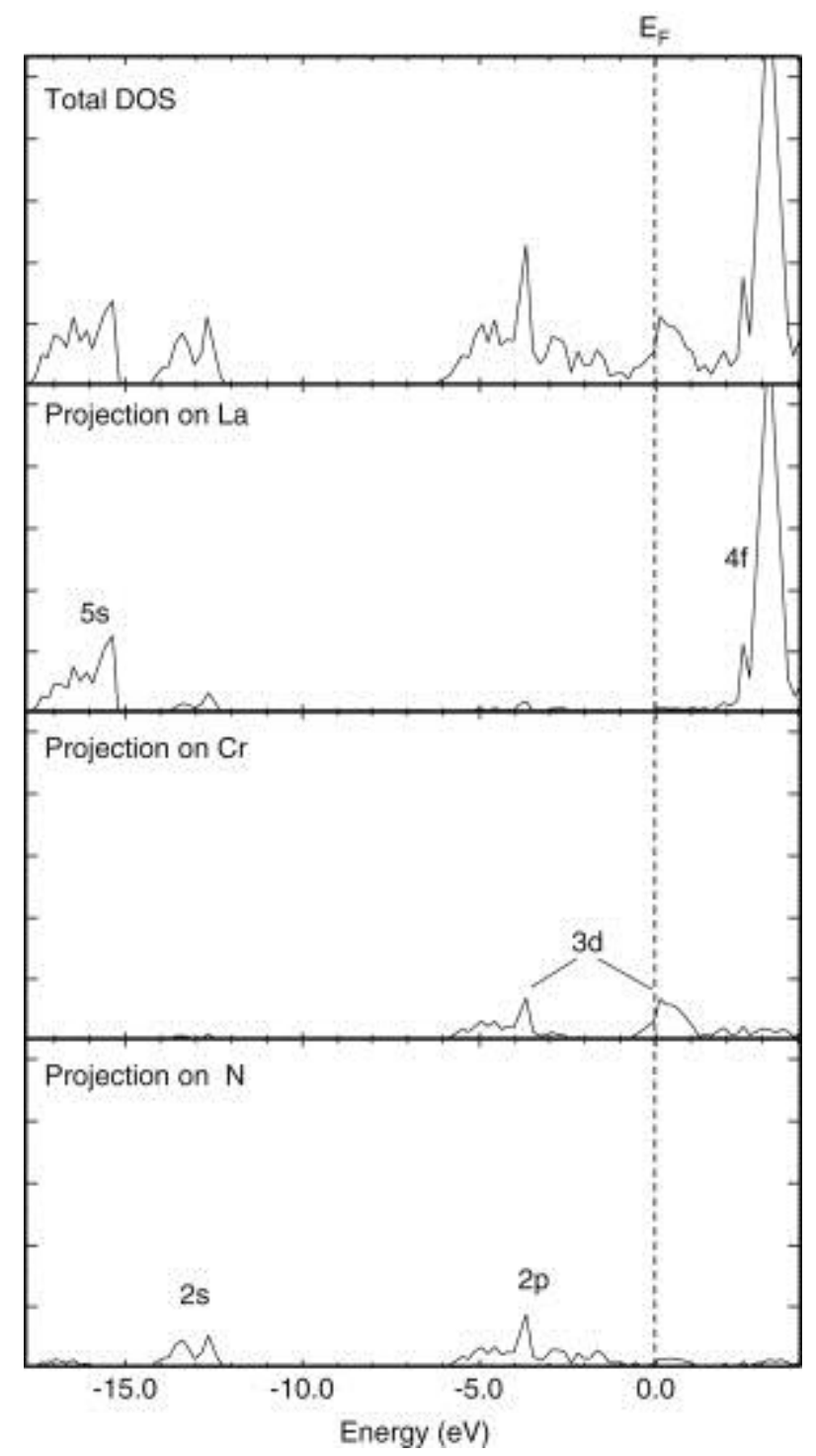


Table 1

\begin{tabular}{|c|c|}
\hline Empirical formula & $\mathrm{La}_{3} \mathrm{Cr}_{2} \mathrm{~N}_{6}$ \\
\hline Formula weight $(M)$ & 604.79 \\
\hline Temperature (K) & $167(2)$ \\
\hline Crystal system & Tetragonal \\
\hline Space group & $I 4 / \mathrm{mmm}$ \\
\hline$a(\AA)$ & $3.8525(5)$ \\
\hline$b(\AA)$ & $3.8525(5)$ \\
\hline$c(\AA)$ & $20.508(4)$ \\
\hline Volume $\left(\AA^{3}\right)$ & $304.38(8)$ \\
\hline$Z$ & 2 \\
\hline Density (calculated) $\left(\mathrm{Mg} \mathrm{m}^{-3}\right)$ & 6.599 \\
\hline Absorption coefficient $(\mu)\left(\mathrm{mm}^{-1}\right)$ & 23.969 \\
\hline $\mathrm{F}(000) \mathrm{F}(000)$ & 522 \\
\hline Crystal size $\left(\mathrm{mm}^{3}\right)$ & $0.10 \times 0.06 \times 0.02$ \\
\hline Theta range for data collection $\left(^{\circ}\right)$ & $1.99-40.64$ \\
\hline Index ranges & $\begin{array}{l}-5 \leq \mathrm{h} \leq 6-5 \leq \mathrm{h} \leq 6 \\
-7 \leq \mathrm{k} \leq 6-7 \leq \mathrm{k} \leq 6 \\
-36 \leq \mathrm{l} \leq 356-\end{array}$ \\
\hline Reflections collected & 3361 \\
\hline Independent reflections & $339\left[R_{\mathrm{int}}=0.0352\right]$ \\
\hline Completeness to theta $=40.64^{\circ}$ & $98.8 \%$ \\
\hline Max. and min. transmission & 0.6457 and 0.3824 \\
\hline Refinement method & $\begin{array}{l}\text { Full-matrix least- } \\
\text { squares on } \mathrm{F}^{2} \mathrm{~F} 2\end{array}$ \\
\hline Data / restraints / parameters & $339 / 0 / 16$ \\
\hline Goodness-of-fir on $F^{2}$ & 1.120 \\
\hline \multirow[t]{2}{*}{ Final $R$ indices $[I>2 \sigma(\mathrm{I})]$} & $R 1=0.0302$ \\
\hline & $\mathrm{w} R 2=0.0746$ \\
\hline \multirow[t]{2}{*}{$\mathrm{R}$ indices (all data) } & $R 1=0.0321$ \\
\hline & $\mathrm{w} R 2=0.0752$ \\
\hline Largest diff. peak and hole (e $\AA^{-3}$ ) & 3.124 and -4.286 \\
\hline
\end{tabular}


Table 2

\begin{tabular}{lllllr}
\hline Atom & Wyckoff position & $x$ & $y$ & $z$ & $U_{\mathrm{eq}}$ \\
\hline $\mathrm{Cr}$ & $4 e$ & 0 & 0 & $0.3987(1)$ & $25(1)$ \\
$\mathrm{La} 1$ & $2 a$ & 0 & 0 & 0 & $14(1)$ \\
$\mathrm{La} 2$ & $4 e$ & 0 & 0 & $0.1838(1)$ & $9(1)$ \\
$\mathrm{N} 1$ & $4 e$ & 0 & 0 & $0.3053(3)$ & $10(1)$ \\
$\mathrm{N} 2$ & $8 g$ & 0 & 0.5 & $0.0863(3)$ & $33(2)$ \\
\hline
\end{tabular}

$U_{\text {eq }}$ is defined as one third of the trace of the orthogonalized $U^{i j}$ tensor.

Table 3

\begin{tabular}{ll}
\hline $\mathrm{Cr}-\mathrm{N} 1 \times 1$ & $1.916(7)$ \\
$\mathrm{Cr}-\mathrm{N} 2 \times 4$ & $1.9505(12)$ \\
\hline $\mathrm{La} 1-\mathrm{N} 2 \times 8$ & $2.616(5)$ \\
\hline $\mathrm{La} 2-\mathrm{N} 1 \times 1$ & $2.491(7)$ \\
$\mathrm{La} 2-\mathrm{N} 1 \times 4$ & $2.7333(7)$ \\
$\mathrm{La} 2-\mathrm{N} 2 \times 4$ & $2.776(5)$ \\
\hline
\end{tabular}

Table 4

\begin{tabular}{lllllr}
\hline Atom & Wyckoff position & $x$ & $y$ & $z$ & $U_{\text {eq }}$ \\
\hline $\mathrm{Cr}$ & $4 e$ & 0 & 0 & $0.3987(1)$ & $25(1)$ \\
$\mathrm{La} 1$ & $2 a$ & 0 & 0 & 0 & $14(1)$ \\
$\mathrm{La} 2$ & $4 e$ & 0 & 0 & $0.1838(1)$ & $9(1)$ \\
$\mathrm{N} 1$ & $4 e$ & 0 & 0 & $0.3053(3)$ & $10(1)$ \\
$\mathrm{N} 2$ & $8 g$ & 0 & 0.5 & $0.0863(3)$ & $33(2)$ \\
\hline
\end{tabular}

$U_{\text {eq }}$ is defined as one third of the trace of the orthogonalized $U^{i j}$ tensor. 